\title{
Editorial
}

\section{Paediatric emergency medicine: Do we need George Clooney?}

Emergency medicine is maturing as a specialty in the United Kingdom. Consequently, areas of subspecialisation are emerging, such as critical care, academic emergency medicine, pre-hospital care, sports medicine and acute general medicine. Paediatric emergency care has received the biggest surge of interest, which is no surprise because children form $25 \%$ to $30 \%$ of patients in most of our departments. This equates to three to four million accident and emergency (A\&E) attendances per year, which is more than are seen in paediatric outpatient clinics. This large paediatric workload means that all A\&E consultants and specialist registrars must possess basic paediatric skills. However, with (slowly) increasing numbers of consultants, larger A\&E departments will in future have a consultant with some additional training in paediatric emergency care.

Over the past decade we have seen significant improvements in paediatric care, for example the mortality from trauma, adjusted for injury severity score, has shown a steady decline. ${ }^{1}$ Paediatric life support courses have proliferated and their basic principles incorporated in teaching at all levels: medical students, doctors and nurses. It is acknowledged, however, that current standards of care for children vary widely across the country and often fall below those taught on paediatric life support courses, or those outlined in the multidisciplinary Working Party Report convened by the Royal College of Paediatrics and Child Health (RCPCH), "Accident and Emergency Services for Children". ${ }^{2}$

The UK government has invested some capital through the A\&E Modernisation Fund, into improvements in facilities, particularly protected waiting and treatment areas. However, it has not invested in the doctors and nurses to staff these areas. The lack of this type of funding means that some of these developments have become "white elephants", and are unsustainable because of dilution of resources. More recently, the UK government has announced ambitious promises in its "NHS Plan". ${ }^{3}$ For us to achieve a better paediatric emergency service, however, we require investment in the infrastructure of the service.

Where paediatric facilities have been developed in A\&E, practice and case mix varies widely depending on geographical location, proximity to children's hospitals, staffing, and the availability of supporting specialties at each site. The role of the A\&E department may range from basic triage with rapid referral, to extensive treatment and investigation within a dedicated, 24 hour paediatric A\&E. Managerial, operational and clinical accountability may rest with either paediatrics or emergency medicine; the doctor initially assessing the child may be a paediatric or an $\mathrm{A} \& \mathrm{E}$ doctor, sometimes depending on the age or presenting complaint of the child. Such variability makes standardisation of practice difficult.

Whatever the configuration of the service, the Working Party document ${ }^{2}$ has set fairly realistic targets for the next decade and has provided useful ammunition for departments seeking to improve their practice. Some targets are more difficult to achieve than others. In particular, it is recommended that A\&E departments seeing more than
18000 new paediatric attendances per year employ a consultant with "additional training" in paediatric A\&E.

There are large numbers of both paediatricians and A\&E specialists who wish to develop their skills further, and the ideal consultant of the future would share the skills of both paediatrics and $\mathrm{A} \& \mathrm{E}$, so that many of the existing arguments about who is "better" at providing such care will cease to exist. In North America specific training schemes have been established for a number of years, the bureaucracy in the UK is delaying the process considerably. It is hard to see how the service can develop to its full potential with the lack of commitment to consultant expansion at national level. The number of SpRs in the UK is restricted, and in the past year paediatrics has had to undergo a reduction in $\mathrm{SpR}$ numbers. Secondly, there is no allowance for a Certificate of Completion of Specialist Training (CCST) in paediatric A\&E in the European Specialist Register. It is hoped that in the future consultants holding CCST in either paediatrics or A\&E will be able to declare a special interest in paediatric A\&E.

Guidelines for training have been agreed by the RCPCH and the Joint Committee on Higher Specialist Training for $\mathrm{A} \& \mathrm{E}$, and are available from the Faculty of $\mathrm{A} \& \mathrm{E}$ Medicine, but have yet to be ratified by the Specialist Training Authority. Structured training should replace the historical "tagging on the end" of general training. With forethought a carefully constructed programme can incorporate paediatric $\mathrm{A} \& \mathrm{E}$ training within, and throughout, the five years of $\mathrm{SpR}$ training, enabling the trainee to acquire different skills (from clinical to managerial) as he or she matures. However, centres providing such training schemes for $A \& E$ SpRs are few and far between, and the situation is worse for paediatric SpRs. Paediatric A\&E consultants derived from the $A \& E$ pathway will take part in the $A \& E$ on call rota, and those derived from the paediatric pathway could join the paediatric on call rota. Hospitals will need to resolve these issues locally.

It is also recommended ${ }^{2}$ that any unit seeing children should employ at least one children trained nurse. There is a national shortage of such nurses, and recruitment and retention are extremely difficult for most departments. Larger units find it easier to attract trained nurses, by developing their own staffing structure, with a more sophisticated skill mix and potential for rotations between "adult A\&E", paediatric ambulatory care or the wards, and offering APLS certification and the paediatric version of the ENB 199 A\&E course, the A88.

So what are the major challenges for the future? Realistically, a move to a totally "Dr Ross" role of seeing only children will not be common practice. This means that $\mathrm{A} \& \mathrm{E}$ trainees need a solid education in paediatric medicine, which may mean increasing the current minimum of three months of paediatric attachment.

There are interesting clinical challenges, such as the neglected area of adolescent care, which may gain some attention once paediatric emergency medicine finds it feet. The 12-19 age group has unique clinical and psychological needs, but is often failed by the artificial divide between "adults" and "children". There is continuing debate around "recipes" for analgesia and sedation, but the recipe is less important than the deeper issues of resources 
(equipment, staff training and availability) and the interface with other specialties.

We will hopefully see progress in academic paediatric emergency medicine, which is still in the very early stages of gestation in the UK, and seems to be far more of an "evidence-free zone" than its adult equivalent. Clinical work of good quality is being produced from many hospitals, but there are no paediatric A\&E academic units as such. Sadly, research in the field of paediatrics, particularly in the emergency environment, carries significant practical problems and provokes huge ethical anxieties. There is considerable pressure from the public and the media to get it right every time.

Reconfiguration of paediatric services means the threat of closure for many smaller paediatric units. The drive to centralisation hinges around cost effectiveness, co-location of services such as those for trauma, as recommended in the report "Better Care for the Severely Injured" and good clinical practice. ${ }^{5-7}$ This has significant implications for $\mathrm{A} \& \mathrm{E}$ departments, as it has been suggested that an $\mathrm{A} \& \mathrm{E}$ should not receive children if there are no inpatient children's services on site. ${ }^{2}$ However, many children, particularly infants and toddler, are not brought to A\&E by ambulance, and ambulance services will still deliver children in cardiorespiratory arrest or severe compromise to the "non-receiving" hospitals. In fact, the A\&E doctors may be the only doctors in that hospital with any experience or training in the care of ill children.

In some parts of the country closing inpatient services has provided an opportunity to develop paediatric ambulatory services. Paediatrics has been ahead of the trend in shifting the emphasis of healthcare from hospital to community, and has succeeded in developing methods of avoiding admission using home care schemes that employ senior paediatric nurses with extended skills, and involving community consultants in more complex care. Some general practitioners may in future choose to undertake either more, or specifically, paediatric work. This provides A\&E with an interesting and satisfying interface for the future.

The national trend towards "one-stop shop" medicine, driven by high public expectation, will result in expansion of the role of the emergency nurse practitioner. The relationship between A\&E departments, Primary Care Trusts, primary care cooperatives and the new walk-in centres has yet to evolve in adult practice, with paediatric practice exposing even thornier issues.

Great progress has been made in paediatric emergency medicine over the past 10 years, and there is room for optimism that our children will in future receive a higher standard of emergency care, and in many cases receive specialist emergency care. Optimum care requires appropriately trained staff, and teamwork. Inpatient teams, primary care, community services, and of course the children and their parents all form part of the "team" that will provide the best outcome for ill and injured children. Emergency medicine doctors have the skills and experience, and are developing the training and academic base to lead and guide this team. Outside the biggest units we probably do not need "Dr Ross", looking after only children in the emergency department. We need a symbiosis of paediatricians with additional expertise in $\mathrm{A} \& \mathrm{E}, \mathrm{A} \& \mathrm{E}$ consultants with additional expertise in paediatrics, and a firm foundation of paediatric experience for all $A \& E$ trainees. Most of all, we need national investment in training the numbers of clinical staff required to deliver the vision of providing the best possible emergency care system for our children.

FFION DAVIES

Accident and Emergency Department, Royal London Hospital, Whitechapel Road, London E1 1BB, UK (Ffion.Davies@Bartsandthelondon.nhs.uk)

1 Roberts I, Campbell F, Hollis S, et al. Reducing accident death rates in children and young adults: the contribution of hospital care. Steering dren and young adults: the contribution of hospital care. Steering
Committee of the Major Trauma Outcome Study Group. BMF Committee of the

2 Accident and Emergency Services for Children. Report of a Multidisciplinary Working Party convened by the Royal College of Paediatrics and Child Health. London: RCPCH, 1999.

3 Department of Health. The NHS Plan- a plan for investment. London: Department of Health, 2000

4 A joint Report from The Royal College of Surgeons of England and the British Orthopaedic Association. Better care for the severely injured. London: Royal College of Surgeons of England, 2000

5 Royal College of Anaesthetists. Guidelines for the provision of anaesthetic services. London: Royal College of Anaesthetists, 1999

6 Report of the National Confidential Enquiry into Perioperative Deaths. Extremes of age. London: 1999.

7 Royal College of Surgeons. Children's surgery - a first class service. London: Royal College of Surgeons, 2000. 